\title{
Evolving the online customer experience... Is there a role for online customer support?
}

Graeme McLean a, *, Alan Wilson b

a University of the West of Scotland, School of Business and Enterprise, Paisley Campus, High Street, Paisley, PA1 2BE, Scotland, UK

b University of Strathclyde, Business School, Stenhouse Wing, 199 Cathedral Street, Glasgow, G4 0QU, Scotland, UK

\begin{abstract}
This paper advances our theoretical understanding with regard to the online customer experience in a utilitarian context. The aim of this research is to understand if there is a need for online customer support during search for information and services on business support websites. In contrast to previous studies highlighting time distortion as part of the optimal customer experience, the findings of this research illustrate that customers are time conscious during a utilitarian search with the perceived length of time spent on the website influencing the customer experience. Additionally, the perceived length of time spent on the website influences the need to seek online customer support. The outcomes of customers requiring online customer support in relation to the customer experience have been established. The findings provide key managerial implications for economic development agencies and online business support providers on the requirement of online customer support and insight into the time conscious nature of customers in relation to the online customer experience.
\end{abstract}

\section{INTRODUCTION}

The Internet has become a fundamental channel of service delivery and how we conduct day-to-day business, yet we remain to have little understanding on the online customer experience (Klaus, 2013). Over recent years the Internet has become the key source for information retrieval and conciliation for both businesses and customers (Flavian-Blanco et al, 2010). The Internet was often regarded as a low cost means of delivering services and a direct channel to communicate with customers (Wang et al, 2010; Chang and Chen, 2008). However, due to technological advances customers now have higher 
expectations within the online environment and expect a high quality level of service (Gronross, 2013). Thus, much of the attention of researchers has been on service quality and its impact on behaviour (Parasuraman et al, 1988). Service quality was once considered as a differentiator between an organisation's services and goods (Edvardsson, 2005), however, Meyer and Schwager (2007) highlight that the service quality of organisations have become increasingly standardised and now the customer seeks more than simply quality service, rather an experience that they are part of and active participants in co-creating value (Vargo and Lush, 2008).

Services delivered online were once considered a relatively impoverished experience due to the inability to interact with service personnel, however the advancements in technology over recent years as discussed by Truel and Connelly (2013) has established new mediums such as live chat technology and online help desks as well as social network channels that offer social interaction and customer support online. Research has shown that in the offline environment, encounters with other customers and with service staff have an influence on the customer's experience during and after the service encounter (Tombs and McColl-Kennedy, 2003). Tombs and McCollKennedy's (2003) research finds that social interactions can give rise to individual's emotions and emotional displays, which in turn can influence the customer's behaviour. Based on social response theory and social presence theory, much recent research within the online environment has highlighted the importance of human-to-computer interactions as customers often see the computer as a social actor rather than simply a channel or medium (Lee and Jeong, 2010; Nass and Moon, 2000). In spite of this, we have little understanding on the need for online customer support in relation to the online customer experience.

Despite the importance of the online customer experience (OCE), only over recent years have researchers developed an interest in exploring the area, thus research remains scant (Ahmed, 2011), with many opportunities to further develop our knowledge. As a result, researchers have called for further exploration on the variables influencing the customer experience as well as 
exploring the outcomes of the customer experience (Verhoef et al 2009; Klaus, 2013).

This research explores the online customer experience in a utilitarian goaldirected context of businesses searching for online business support information and services on business support websites. Business support providers offer business support services on business growth, leadership, developing employees, tax, legal obligations, funding and day-to-day advice on running a business. With over 1 billion searches worldwide each month around keywords of business support (Alexia 2015), in addition to the economic impact of businesses receiving effective online business support services, managers need to understand variables capable of influencing the customer's.

The objectives of this paper are:

1) Understand the length of time customers are willing to spend during a goal directed search for information and services on business support websites.

2) Examine the requirement of online customer support during a utilitarian search for business support information and services.

3) Explore the role of customer emotions in relation to the online customer experience during a goal directed utilitarian search.

4) Develop a theoretical framework advancing our understanding on the OCE

This paper will be structured as follows; first of all we will introduce and discuss the existing literature with regard to the offline and online customer experience, the length of time customers are willing to spend on a website and the role of customer support. Further to this we discuss the study's methodological approach, before going on to highlight the findings and present our theoretical framework. Finally theoretical and managerial implications of the research will be outlined followed by the study's limitations and directions for future research. 


\section{LITERATURE REVIEW}

\section{Customer Experience}

Satisfaction, trust, re-visit intention, re-purchase intention and loyalty have all been identified as outcomes of a positive customer experience (Verhoef et al 2009; Badgett et al 2007), thus the customer experience is considered an important area of research. Over recent years the focus of service research has been on assessing service quality and its impact on customer behaviour (Parasuraman et al 1988). SERVQUAL, a multi item scale has been deployed by numerous researchers over recent years in the attempt to measure service quality in a multitude of contexts. Verhoef et al (2009) outline that a focus on the customer experience is of the upmost importance to organisations in order to have a competitive advantage, moving beyond that of assessing service quality.

A key distinction between the customer experience and service quality is the acknowledgement of customer emotions within the customer experience (Edvardsson et al 2007; Lee and Lin 2005). Services researchers have applied psychology theories in adopting the PAD model of affect (Mehrabian and Russell 1974), the PANAS theory (Watson et al 1988) and the differential emotion theory (Izard 1977), to aid in the understanding of the customer experience. Prior to this, service quality research focused solely on cognitive assessments, ignoring the role of customer's emotions (Edvardsson 2005). Voss et al (2008) highlights that the customer experience is a holistic process made up from the customer journey, deriving from the sequence of touchpoints a customer has with an organisation. Kuhlthau (2004) highlights that during a search for information a customer's emotions are a critical part of influencing the customer's decision-making and behaviour.

Berry et al (2002) comment that customers always have an experience; this experience may be good, bad or indifferent and occurs whenever a customer 
buys a product or encounters service from an organisation. Early research on customer experience focussed on experiential activities of hedonic value (Schmitt, 1999). However, Vargo and Lush (2006) in line with Berry et al (2002) highlight that an experience is a key part of a utilitarian activity and thus research is required in both contexts. The theoretical basis of the customer experience is found on the concept that the customer experience is the combination of all cues and touch-points with an organisation to create an overall experience (Payne et al 2008; Mossberg 2007). However, Klaus (2013) points out that much of the research examining the online customer experience relies on conceptual thinking and thus a need for empirical research exists.

\section{Online Customer Experience}

Understanding the customer's perception of the online environment and assessing overall service quality has continued to be the focus of studies researching online customer behaviour (Klaus, 2013). Numerous researchers continued to focus on customers' perceptions of service quality using ESERVQUAL (Parasuraman et al 2005), the online extension of the original SERVQUAL multi-item scale. However just like the offline environment the focus of research is shifting towards the online customer experience (Nambisan and Watt, 2011). This shift has somewhat established from the transition of website development in the change from static websites (both ecommerce and informational sites) to dynamic and interactive websites offering customers the ability to customise and interact with the online web environment. Previous research posits that providing an exceptional online experience will positively influence a customer's online behaviour

Originally, Hoffman and Novak (2009) explore the online customer experience (OCE) from a cognitive view of online interaction. Novak et al (2000) define the online customer experience as a cognitive state experienced during navigation. However, in line with research within the offline environment, Rose et al (2012) outline the importance of customer emotions during the online experience. Flavain-Blanco et al (2012) find that customer emotions are 
prevalent in the online environment prior, during and post search and often cause customers to abandon their online activity. Thus, Rose et al (2012) posit that the customer engages in cognitive and affective processing of incoming sensory information from the online environment, which subsequently results in the formation of an impression that is stored in the customer's memory.

The concept of flow has received much attention within the online environment with regard to the OCE (Hoffman and Novak, 2009). Previous studies have highlighted flow as a practical way of understanding how customers interact with the web environment (Smith and Sivakumar, 2004). However, the usefulness of the concept of flow in goal directed circumstances has been questioned (Klaus, 2013; Hoffman and Novak, 2009). The majority of literature with regard to the CE and the OCE has focused on the hedonic activity of online shopping. However, Cho and Park (2001) posit that online customers should not just simply be considered as shoppers but also information seekers and users of technology. Thus, we can consider that the OCE is more complex than the online shopping experience (Constantinides et al, 2010). Weinreich et al (2008) highlight that we are still in the infancy of understanding the way customers act within the online environment, as such there is no clear understanding or definition of the experiential variables of a web site and its environment (Demangeot and Broderick, 2006). While current conceptualisations within the CE and the OCE is comprehensive, Klaus (2013) suggests that the customer experience may be context specific and thus different dimensions of the customer experience exist, where variables may influence customers in a context specific setting.

\section{Perceived length of time Spent on the website}

The concept of flow is often closely associated with telepresence and time distortion (Hoffman and Novak, 2009). Recent literature has revealed much debate around the concept of flow involving antecedents and consequences of flow. Numerous researchers highlight telepresence and time distortion as both antecedents and consequences of flow. 
Lee et al (2011) suggest that telepresence is a feeling of being present in a virtual environment that is more dominant than the actual real life physical world that the individual lives in and has the potential to influence a customer while operating in the online environment. Hoffman and Novak (2009) suggest that individuals experiencing telepresence forget about their immediate surroundings when searching online, while an individual's body may be in a physical room or environment, their mind is in the 'virtual space' in which the individual is engaged in and often the individual can find the virtual world more real than their real life world. Faiola et al (2013) argue that telepresence may be a critical aspect of users feeling the sense of 'being there' in other words being completely immersed and engaged in the activity they are completing, in turn experiencing a distorted sense of time (being unaware of time passing) and multiple positive emotions. In the cognitive mental state described of telepresence, the individual is transported to a virtual environment where their connection with real time and space slowly fades away into the background of consciousness.

Similarly, time distortion refers to the point where customers are so involved in the activity that time elapses rapidly for them (Fan et al, 2013). Time distortion is often seen as a key part of flow and used to define flow (Skadberg and Kimmel, 2004). Hoffman and Novak (2009) refer to time distortion as the sense of distortion in time perception, where the customer is unaware of time passing, so that time appears to pass more quickly and to an extent unconsciously to the customer and results in a positive customer experience.

However, as previously mentioned the usefulness of flow and variables of time distortion and telepresence have been called into question in a goal directed activity (Klaus, 2013; Hoffman and Novak, 2009). Klaus (2013) highlights that the customer experience may be context specific and thus in a goal directed utilitarian activity customers may actually be time conscious rather than unaware of time passing (McLean and Wilson, 2015). Thus, due to the need for context specific research within the OCE, the area remains in its infancy. 


\section{Online Customer Support}

Interactions with service staff occurs on a regular basis in the offline environment, however in the online environment customers are often left to service themselves, yet organisations aim to provide customers with the optimal experience. Kuhlthau (1994) highlighted that intervention by service providers may aid individuals in their search for information. Kuhlthau's (1994) work on the zone of intervention outlines the importance of social interaction with others in order to move through the search process. Information on a website may be considered as being in an ordered and certain fashion, in contrast however an individuals search task or need is characterised by uncertainty and confusion (Kuhlthau, 2004). As a result it can be seen that a gap often exists between a website's provision of information and a users natural process of information search and use. The adoption of technology to provide customer support services are increasing in order to meet customer's evolving needs (Truel and Connelly, 2013). These services allow customers to seek service-related information from a company via web-based synchronous media (typically live chat facilities, online help desks and social network websites), and a human service advisor who provides assistance via the same media (Turel et al, 2013).

Interactivity theory highlights a role for communication online (Rafaeli, 1988). Song and Zinkhan (2008) posit that the perception of communication can result in users having an enhanced overall experience. Liu and Shrum (2002, pp.54) discuss social interaction as communication between two individuals, 'the degree to which two or more communicating parties can act on each other, on the communication medium, and the message and the degree to which such influences are synchronised'. Kuhlthau's (1996) research points out the need to communicate with service providers during a medium to complex search for information. McMillan and Hwang (2002) stress that communication online provides an effective form of online customer support, thus assisting customers online. Truel et al (2013) have advanced such research by suggesting that online support can act as a full customer service platform and a form of service recovery should customers not encounter 
effective service delivery. Papadopoulou (2007) highlights that the online environment can become a real world equivalent for service providers where a full social experience can be delivered in line with what occurs in the 'real world'.

Some service provides are now utilising technology in order to provide customer service and support online (Truel et al, 2013). Previous research has illustrated in the offline environment, encounters with other customers and with service staff have an influence on the customers experience during and after the service encounter (Tombs and McColl-Kennedy, 2003). Based on social response theory and social presence theory, much recent research within the online environment has highlighted the importance of human-tocomputer interactions as individuals often see the computer as a social actor rather than simply a channel or medium (Lee and Jeong, 2010; Nass and Moon, 2000; Reevs and Nass 1994). In the context of offline information seeking it can be seen that individuals often have interactions with other humans. However, in an online context this interaction can be somewhat limited (Hassanein and Head, 2007). While the technology exists to provide online customer support through a variety of channels, little is known on its usefulness, need and influence in relation to the online customer experience, to which this study will address this research gap.

\section{RESEARCH HYPOTHESES}

Through the gaps emerging from the literature, five research hypotheses have been developed. We have little understanding on the length of time customers are willing to spend searching for business support information and services. Previous research has highlighted time distortion as being a key part of a positive customer experience, where customers are not conscious of the length of time spent on the website, however McLean and Wilson (2015) point out that customers may in fact be time conscious within the online environment during a utilitarian search in contrast to previous research. Thus we posit $(\mathrm{H} 1)$ should customers be required to spend longer than perceived necessary searching on a business support website for information and 
services they will require online customer support through synchronised media and (H2) should customer be required to spend longer than perceived necessary searching for information and services they will be dissatisfied with their experience.

Previous studies have highlighted customer emotions as influencing customers' online behaviour (Rose et al, 2012). Kuhlthau et al (2008) posit that negative customer emotions often result in customers abandoning their search. However, we have little understanding on a customer's need to seek online customer support in relation to customer emotions, thus we suggest (H3) customers requiring online customer support during search on a business support website will result in customers having negative emotions. Additionally, we posit ( $\mathrm{H} 4)$ positive customer emotions will result in customer's being satisfied with their experience during a goal directed utilitarian search for business support information.

Previous research has outlined that customer support can be provided online (Truel and Connelly, 2013) through the use of live chat functions and online help desks. Kuhlthau (2004) points out that intervention is often required during search, however we have little knowledge with regard to the impact of requiring online customer support in relation to the customer experience, thus we posit (H5) customers who require seeking online customer support with a service representative will be dissatisfied with their experience.

\section{METHODOLOGY}

In order to answer the research objectives and examine the hypothesised relationships outlined, an online experiment was conducted on three-selected government provided business support websites with a sample size of 160 participants. Three tasks were set for participants to complete on each website experiment $(3 \times 3)$. Participants were provided with a business scenario and information or services to find. Participants were given 6 minutes for the 3 tasks on each website, 18 minutes in total, with the experiment and questionnaire taking a combined 36 minutes on average to complete. Figure 1.0 provides a graphical representation of the experiment procedure. 
Figure 1.0 Online Experiment Procedure

\begin{tabular}{|c|c|c|}
\hline Experiment 1 & Experiment 2 & Experiment 3 \\
\hline Task 1 & Task 1 & Task 1 \\
\hline Task 2 & Task 2 & Task 2 \\
\hline Task 3 & Task 3 & Task 3 \\
\hline $\begin{array}{l}\text { ( } 6 \text { minutes given to } \\
\text { complete all tasks) }\end{array}$ & $\begin{array}{l}\text { (6 minutes given to } \\
\text { complete all tasks) }\end{array}$ & $\begin{array}{l}\text { (6 minutes given to } \\
\text { complete all tasks) }\end{array}$ \\
\hline $\begin{array}{c}\text { Answer } \\
\text { Questionnaire }\end{array}$ & $\begin{array}{c}\text { Answer } \\
\text { Questionnaire }\end{array}$ & $\begin{array}{c}\text { Answer } \\
\text { Questionnaire }\end{array}$ \\
\hline
\end{tabular}

In addition, help cards were issued to participants that could be used during their search to find information and services. The help cards were symbolic and illustrated when help through customer support would be useful and allowed the researcher to identify how often customers would actually seek online customer support, whilst not having to amend the websites through integrating online customer support functions. Thus, during the tasks participants could have one of three outcomes; complete their task and move onto the next task, use a help card and move on to the next task or abandon their task and move onto the next task.

Using an online experiment provided each respondent with the experience of searching for business support services across three different business support websites. Data were collected through a web-based questionnaire immediately after the completion of each experiment.

In order to test the hypothesised relationships in the study, structural equation modelling (SEM) was adopted using AMOS Graphics 22. Due to the online questionnaires being research administered, all 160 responses were usable with no missing data, which is consistent with the sample required for SEM 
(Byrne, 2013). The benefit of structural equation modeling is that the hypothesised model can be tested statistically in a simultaneous analysis of the whole model of variables (Byrne, 2013). The sampling frame consisted of a mix of business people, undergraduate and postgraduate business students within the UK. The sample achieved a relatively even split between males (47\%) and females (53\%). In terms of age group, the study achieved a good representation of ages in relation to customers of an economic development agency, 18-25 (37\%), 26-34 (28\%), 35-42 (18\%), 43-50 (14\%) and 50+ (4\%). On average participants were fairly knowledgeable and relatively confident at using the Internet.

The questionnaire scales were adapted from established scales from within the literature to measure customer emotions, the requirement for online customer support and the level of satisfaction with the experience. All survey items used in the study were measured on a five-point Likert scale ranging from (1) Strongly Disagree to (5) Strongly Agree. One new scale was developed to measure the perceived length of time spent on the website. This new scale was developed in line with Churchill's (1979) scale development procedures. In line with theory development experts, if we are unable to answer research questions through established scales we should develop new scales to advance our theoretical understanding (Dubin, 1971). While scales may be developed using a single item measure (Jacoby, 1978), Churchill (1979) suggest that researchers are far better served to develop a multi-item scale as has been done in this study. From a review of the literature no adequate scale could be adopted in order to measure a customer's perceived adequate length of time to spend searching on the website.

Measuring the 'perceived' length of time spent on the website is important due to customers' perception of the actual appropriate length of time to spend on the website in minutes will vary. However, the variable itself remains important to explore. Table 1.0 outlines the scales and their items used in this paper. 
Table 1.0 Measurement Scales

\begin{tabular}{|c|c|c|c|}
\hline Variable & $\begin{array}{l}\text { Scale } \\
\text { Reference }\end{array}$ & Adapted Scale & $\begin{array}{l}\text { Cronbach's } \\
\text { Alpha }\end{array}$ \\
\hline $\begin{array}{l}\text { Perceived } \\
\text { Length of } \\
\text { Time Spent } \\
\text { on the } \\
\text { website }\end{array}$ & $\begin{array}{l}\text { New Scale } \\
\text { Developed }\end{array}$ & $\begin{array}{l}\text { I spent more time than I would have liked } \\
\text { searching for the information. } \\
\text { - It took longer than I expected to find the } \\
\text { information on the website. } \\
\text { It took too long searching for the } \\
\text { information on the website. } \\
\text { The length of time spent searching for } \\
\text { information on the website was acceptable. }\end{array}$ & .871 \\
\hline $\begin{array}{l}\text { Positive } \\
\text { Emotions }\end{array}$ & $\begin{array}{l}\text { Adapted from } \\
\text { Kuhlthau } \\
\text { (2004) and } \\
\text { applied a Likert } \\
\text { Scale: } \\
\text { Following the } \\
\text { PANAS scale }\end{array}$ & $\begin{array}{ll}\text { - } & \text { (R)Frustrated } \\
\text { - } & \text { Confident } \\
\text { - } & \text { Sure } \\
\text { - } & \text { (R)Confused } \\
\text { - } & \text { Optimistic } \\
\text { - } & \text { (R)Uncertain } \\
\text { - } & \text { (R)Disappointed } \\
\text { - } & \text { Relieved } \\
\text { - } & \text { (R)Doubtful } \\
\text { - } & \text { Satisfied }\end{array}$ & .968 \\
\hline $\begin{array}{l}\text { Level of } \\
\text { Satisfaction }\end{array}$ & $\begin{array}{l}\text { Song and } \\
\text { Zinkhan (2008) }\end{array}$ & $\begin{array}{l}\text { I am satisfied with the experience. } \\
\text { - This online experience is exactly what I } \\
\text { needed. } \\
\text { (R)This online search experience has not } \\
\text { worked out as well as I thought it would. }\end{array}$ & .902 \\
\hline $\begin{array}{l}\text { Social } \\
\text { Interaction } \\
\text { (Customer } \\
\text { Support) }\end{array}$ & $\begin{array}{l}\text { Khulthau } \\
\text { (2004); Lui } \\
\text { (2003); } \\
\text { McMillan and } \\
\text { Hwang (2002); } \\
\text { Song and } \\
\text { Zinkhan, } \\
\text { (2008). }\end{array}$ & $\begin{array}{l}\text { - It would have been useful to be able to ask } \\
\text { for direction in locating the information. } \\
\text { - It would have been useful to be able to talk } \\
\text { to people who know about the topic. } \\
\text { It would have been useful to ask for advice } \\
\text { while searching for the information. } \\
\text { - It would have been useful to have } \\
\text { assistance in identifying the correct } \\
\text { material. } \\
\text { - It would have been useful if the website } \\
\text { facilitated two-way communication... } \\
\text { It would have been useful if the website } \\
\text { gives me the opportunity to talk back... } \\
\text { It would have been useful if the website } \\
\text { facilitates instant (live) communication... } \\
\text { - It would have been useful if the web site } \\
\text { enabled conversation. }\end{array}$ & .986 \\
\hline
\end{tabular}

\section{RESULTS}


Several analyses were preformed before going on to estimate the research model using SEM. First of all a repeated measures ANOVA was conducted between business people and postgraduate/undergraduate business students across the three experiments to identify if any differences existed between the responses of the two groups on the variables within the study. The results of this test showed that there was no statistical significant difference between business people and business students, Wilks' Lambda $=.40, f(20.00,20.00)$ $=1.514, p=.181$. Thus, as a non-significant result was achieved $p=>.05$ (.181) therefore, it can be concluded that there is no difference in responses to the questions within the questionnaire between business people and business students across all 3 experiments. Thus, the sample used in the study can be deemed as being appropriate. Additionally, a second repeated measures ANOVA was conducted to identify if any differences existed between the three websites used in the study. The results showed, Wilks' Lambda $=.19, f(20.00,140.00)=29.920, p=.000$, which can therefore be concluded as a significant statistical difference as the $p$ value is $<.05$. As a result, this provides the study with a broad and representative set of websites that can produce generlisable results for economic development agencies operating business support websites.

Secondly, scale reliability tests and data normality tests were conducted prior to structural modelling. In order to conduct reliability tests cronbach's alpha coefficient was calculated. The value for each scale was above the critical value of .7 (Pallant, 2013), thus the scales offer discriminant validity. Table 1.0 outlines the Cronbach's alpha values in relation to the scales used in the study. In order to determine if the data are normally distributed, a z-score from the skewness and kurtosis values need to be calculated, this is done by dividing the skewness and kurtosis values by their standard error. The z-score for each variable falls between the values of -2.58 and +2.58 after a conservative statistical significance level of .01 is set, therefore the data can be considered as normally distributed.

\section{Structural Equation Modelling}


Structural Equation Modelling (SEM) was adopted in this study with the use of AMOS 22. Structural equation modelling with an analysis of moment structures is one of the most commonly used statistical techniques that is adopted in order to conduct analysis on structural theory through a confirmatory approach (Tabachnick and Fidell, 2007). Structural Equation Modelling involves two important aspects (1) that the casual process that is being studied is represented by a series of structural (regression) equations and (2) the structural relationships can be modelled pictorially to provide a clear representation of the theory being studied.

Structural equation modelling is conducted in two steps, first the measurement model and second the structural model. The CFA measurement model outlines the causal relationships between the observed variables and the underlying latent variables. The structural model on the other hand outlines the casual relationships of the theoretical constructs between exogenous and endogenous variables or among endogenous variables. Therefore in the first step of the structural equation modelling, the CFA measurement model was specified and estimated. The fit statistics of the model were good $(\mathrm{CFI}=.960, \mathrm{NFI}=.954, \mathrm{GFI}=.949, \mathrm{SRMR}=.040, \mathrm{RMSEA}$ $=.047, \mathrm{RMR}=.015)$. Further to the fit statistics all loadings were adequate and significant at $p=.000$.

Thus, due to a good fitting measurement model, the study can proceed to the second step, which involves the specification and estimation of the hypothesised structural model as shown in figure 1 . The fit statistics of the structural model showed goodness of fit $\left(x^{2}=2.91, \mathrm{CFI}=.996, \mathrm{NFI}=.993\right.$, $\mathrm{GFI}=.991, \mathrm{SRMR}=.017, \mathrm{RMSEA}=.049, \mathrm{RMR}=.010)$ and support the hypothesised relationships. In addition the standardised path coefficient regression weights, standard error and statistical significance are shown in table 2.0 and figure 2.

Table 2.0 SEM Regression Estimates

\begin{tabular}{|c|c|c|c|c|c|}
\hline & & & Estimate & S.E & $\mathrm{P}$ \\
\hline Seek online customer & $\begin{array}{l}<-- \\
\end{array}$ & Perceived length of time & .541 & .059 & $* * *$ \\
\hline
\end{tabular}




\begin{tabular}{|c|c|c|c|c|c|}
\hline & & & Estimate & S.E & $\mathrm{P}$ \\
\hline support & & spent on the website & & & \\
\hline $\begin{array}{l}\text { Satisfaction with the } \\
\text { experience }\end{array}$ & $<--$ & $\begin{array}{l}\text { Perceived length of time } \\
\text { spent on the website }\end{array}$ & -.513 & .047 & $* * *$ \\
\hline $\begin{array}{l}\text { Satisfaction with the } \\
\text { experience }\end{array}$ & $<--$ & $\begin{array}{l}\text { Seek online customer } \\
\text { support }\end{array}$ & -.662 & .068 & $* * *$ \\
\hline $\begin{array}{l}\text { Positive Customer } \\
\text { Emotions }\end{array}$ & $<--$ & $\begin{array}{l}\text { Seek online customer } \\
\text { support }\end{array}$ & -.762 & .059 & $* * *$ \\
\hline $\begin{array}{l}\text { Satisfaction with the } \\
\text { experience }\end{array}$ & $<--$ & $\begin{array}{l}\text { Positive Customer } \\
\text { Emotions }\end{array}$ & .803 & .058 & $* * *$ \\
\hline
\end{tabular}

\section{Figure 2.0 Structural Equation Model}

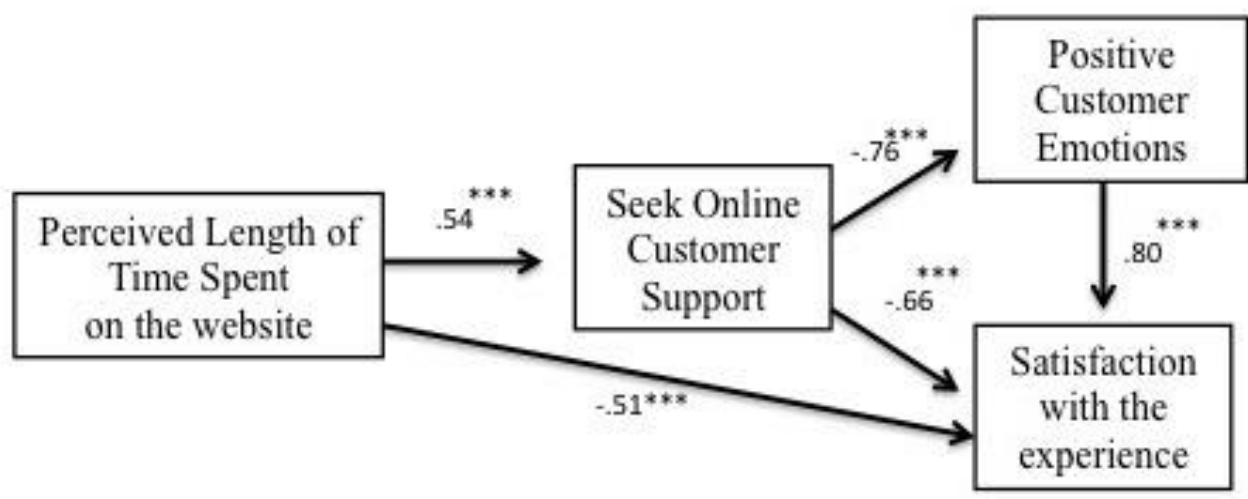

The results outlined in table 2.0 and figure 2.0 outline strong regression coefficients and statistically significant relationships proving each of the research hypotheses.

In addition to the structural equation model shown in figure 1.0 outlining the need for seeking online customer support, the help cards issued to participants during the online experiment further support the need for online customer support through synchronized media with a service representative. The help cards provided practical (in action) evidence of the requirement of online customer support during a customer's online experience. Table 3.0 provides a summary of the use of 'help cards' during the online experiments.

Table 3.0 Summary of Help Card Usage During Online Experiments

\begin{tabular}{|l|l|l|l|}
\hline Experiment & Task & $\begin{array}{l}\text { Number of } \\
\text { participants }\end{array}$ & $\begin{array}{l}\text { (N) Help Card } \\
\text { Used }\end{array}$ \\
\hline
\end{tabular}




\begin{tabular}{|l|l|l|l|}
\hline & $\begin{array}{l}\text { who attempted } \\
\text { tasks }\end{array}$ & \\
\hline Exp1 & Task1 & 160 & 80 \\
\hline & Task 2 & 159 & 45 \\
\hline Total & Task 3 & 85 & 6 \\
\hline & & $\mathbf{4 0 4}$ & $\mathbf{1 3 1}$ \\
\hline Exp2 & & & \\
\hline & Task 1 & 160 & 75 \\
\hline & Task 2 & 160 & 34 \\
\hline Total & Task 3 & 89 & 9 \\
\hline & & $\mathbf{4 0 9}$ & $\mathbf{1 1 8}$ \\
\hline Exp3 & & & \\
\hline & Task 1 & 160 & 90 \\
\hline & Task 2 & 157 & 82 \\
\hline Total & Task 3 & 46 & 8 \\
\hline & & $\mathbf{3 6 3}$ & $\mathbf{1 8 0}$ \\
\hline Overall Total $(\mathrm{N})$ & & & \\
\hline Overall Total $(\%)$ & & $\mathbf{1 , 1 7 6}$ & $\mathbf{4 2 9}$ \\
\hline
\end{tabular}

Table 3.0 outlines that $36 \%$ of 1,176 attempts at tasks illustrated that they would have liked customer support while trying to complete their task. In addition to the structural model the findings outline significant evidence for online customer support.

Due to the methodological approach the study was able to capture the point in time that help cards were used to signify the need for online customer support. The mean average time participants used help cards across the three websites was at 2 minutes and 11 seconds. The findings illustrate a standard deviation of .61, therefore this suggest that the optimal range in offering online support is between 1 minute 10 seconds and 3 minutes 12 seconds.

\section{DISCUSSION}

Customers operating within the online environment are becoming more demanding and expecting a higher level of service in a timely manner. The once considered impoverished experience of the Internet due to the inability to interact with service personnel is somewhat diminishing with the 
advancements in technology due to functionality such as live chat, online help desks and social network channels that offer the ability to provide online customer support. However, the requirement for such online support has yet to be examined empirically. This study has made the initial strides in exploring the area in relation to the online customer experience. Like the offline environment, the findings highlight that online customers often need the assistance of service staff. In addition, this study has introduced the importance of the length of time customers perceive to spend searching on a website as driving the need for online customer support and effecting the customer experience. Previous research highlighted time distortion and telepresence as notions where customers would be unaware of time passing. However in stark contrast this study finds that customers are highly time sensitive in the online environment during a goal directed utilitarian task. Thus, in line with customers becoming more demanding in the online environment where service providers are required to provide customers with a positive experience, customers of business support websites expect to find information quickly due to their time conscious online behaviour. As a result numerous theoretical and managerial implications have arisen from this research.

\section{Theoretical Implications}

A number of theoretical implications should be emphasised from this research. The findings have extended our limited knowledge on the online customer experience and online web behaviour. The findings first of all illustrate that customers are time conscious during a goal directed utilitarian search for business support information and services, thus customers are not willing to spend longer than they perceive necessary searching on a business support website. Previous research highlights (Fan et al, 2013; Hoffman and Novak, 2009) that customers become unaware of time passing in the online environment and in turn the 'time distortion' experienced has a positive effect on the customer experience, however these studies have been conducted in the context of online shopping, thus we have extended our theoretical understanding of online behaviour and the online customer experience and 
found that during a utilitarian search, customers are time conscious and therefore expect to complete their task in a timely manner. In the situation where customers are required to extend beyond the length of time perceived necessary to complete their task will result in customers becoming dissatisfied with their experience. As a result the notion of time distortion in the online environment is context specific.

Previous studies have overlooked the role of the perceived length of time spent on the website as having an effect on the customer experience. This study has found that the perceived length of time spent on the website has a direct and indirect effect on the customer's level of satisfaction with their experience. Therefore should customers' believe that they are required to spend longer than perceived necessary they will have a negative experience and abandon their search on the website. Previous studies outlined that customers lose the sense of time while operating within the online environment, however this finding illustrates that during a utilitarian search customers are time conscious influencing their behaviour and experience in the online environment.

Moreover, the length of time customers are required to spend during a utilitarian search has an effect on their need to seek online customer support. Customers who are required to spend longer than they perceive necessary require online customer support with a service representative. Previous studies outline that customers can be supported online through socially interacting with a service representative via technological functions such as live chat, online help desks and social networking sites (Truel and Connelly, 2015), however there is little understanding on the need for such functions and what drives the need for participation with such functions. In addition to the structural model, through the use of the help cards deployed in the online experiment, it was found that there is an apparent need for online customer support during a utilitarian search for business support information and services. The findings illustrate that a customer's perception of spending longer than they perceive as being necessary drives the need for online customer support. From the use of the help cards during the online 
experiment, it can be seen that the average time customers used a help card was at 2 mins and 11 seconds, this illustrates that customer's will conduct a search on the website before directly seeking customer support, however the findings show that during this search customers are conscious of the time they are spending, which ultimately drives the need to seek online customer support.

However, the need to seek online customer support could be considered paradoxical as the requirement informs that customers are not encountering a positive online experience and are unable to complete their task alone without the assistance of service personnel. The findings illustrate that customers who require online customer support will have negative customer emotions of frustration, confusion, doubt and disappointment in the experience. Thus, the requirement of online customer support in order to complete a task illustrates that customers are dissatisfied with their experience. However, in spite of this, online customer support may provide the service recovery required in aiding customers and directing them to the services and information required. Thus, an online customer support function may help customers in overcoming negative emotions expressed during search.

In line with studies examining the offline customer experience (Edvardsson et al, 2005) and the online customer experience within the online shopping environment (Rose et al, 2012; Klaus, 2013), this study finds that a customer's emotions have an effect on the level of satisfaction with the experience in a goal directed utilitarian context. Negative emotions induced by the perception of spending too long on the website has a significant negative effect on the customer experience. However, in contrast should customers experience positive emotions online, it will result in overall satisfaction with the experience. As previously discussed it can be seen that the perceived length of time spent on the website mediated by the need to seek customer support has an effect on customers' emotions in the online environment. 
The findings from this research provide us with an insight into the need for online customer support functions as well as the outcome of the requirement to seek online customer support. Previous research has outlined the technology that can be used to provide online customer support (Truel and Connelly, 2013). Greenberg (2010) highlighted the social customer as a customer who expects to be able to interact online. This study has developed this conceptual thinking through empirically establishing a need for online social interaction through customer support with service representatives during a utilitarian search for online information and services. Despite the previously mentioned paradox of requiring online customer support resulting in customers having a negative online experience and service providers needing to deliver online customer support to meet customer requirements and expectations. The actual usage of online customer support may provide the service required to prevent customers abandoning their search as seen with participants in this study through the use of help cards. Participants of the online experiment illustrated that they would abandon their search if customer support was not available.

\section{Practical Implications}

This study offers online business support providers and economic development agencies numerous practical implications. Much industry research refers to the importance of customers spending a prolonged period of time on the website as a benchmark of a successful website. This study highlights to marketers and managers of business support websites to use such a benchmark with caution as the findings illustrate that individuals conducting goal directed tasks are time conscious. Thus, the longer customers are required to spend searching on a website will result in the customer having a negative experience as well as an unsuccessful search. As a result, managers should offer business support websites that allow customers to complete their tasks in a timely manner.

As has been previously discussed, a distinctive difference between the online and offline environment is the ability to socially interact with a customer 
representative. With the advancements of recent technology, new features such as live chat technology and online customer helpdesks allow organisations to offer customer support online. This research found that customers who are required to spend longer than perceived necessary searching on a business support website require online customer support through synchronised social interaction with a service representative. The need to seek online customer support highlights that customers are dissatisfied with their online experience, while experiencing emotions of frustration, uncertainty, doubt and disappointment. In spite of such a negative connotation, customer support through live chat, online help desks or social networking websites may provide customers with the service recovery required, simply providing customers with information and self-service functions may be a disservice to customers. The results outlined the optimal range of proactively providing online customer support to web users from 1 minute 10 seconds to 3 minutes 12 seconds (the standard deviation from the average time help cards were used). However, whether a proactive or reactive approach is adopted, the introduction of online customer support function may help to prevent customers abandoning their search and provide the service customers now expect.

\section{LIMITATIONS AND FUTURE DIRECTIONS}

The findings and implications of this study are somewhat constrained by certain limitations, some of which provide opportunities for future research. While the online experiment outlined actual behaviour with regard to online customer support through the use of help cards. In order to further explore online customer support via synchronised social interaction, researchers ought to develop a website with online customer support compatibility such as a 'live chat' function and one without to compare the difference on the customer's experience after use of an online customer support function. This study found the outcome of 'needing to seek' online customer support. Future research could advance the research undertaken in this study through establishing the outcome of actual use with an online customer support function. 
Additionally, this study focuses on a specific service setting, while it would seem reasonable that the findings identified would extend to similar utilitarian service settings, further research on the newly established variable of the length of time customers are willing to spend on the website in other service settings (utilitarian and hedonic) may prove fruitful in order to develop our theoretical understanding, as customers are becoming more demanding we may be seeing the rise of time conscious customers. Additionally, this research has found that online customer support is required if a customer perceives to spend longer than necessary searching on the website. It would be valuable for future research studies to explore if a role for online customer support exists within other utilitarian and hedonic contexts.

Lastly the model produced in this research is not conclusive. Future research can extend the model through introducing other aspects that may be influential in influencing the online customer experience and the need for online customer support (e.g. website aesthetics, level of control and information quality).

\section{CONCLUSION}

Providing an effective online customer experience continues to be a challenge for service providers. While technology has provided new online service delivery channels, little is known on what influences the online customer experience, the results from this research have furthered our understanding. This study has illustrated the importance of acknowledging time conscious customers in a utilitarian context and its impact on the online customer experience. Additionally the requirement of online customer support has been established in the online environment during a search for business support information and services, the outcomes of requiring online customer support have been established. Future research should explore the impact of online customer support on the online customer experience after its use. It is hoped that this study serves as a platform for such future research projects into the role of online customer support through synchronised media. 


\section{References}

Ahmed, R. I. (2011) 'Experience Marketing: An Empirical Investigation', Journal of Relationship Marketing, 10, 167-201.

Alexa (2015) 'Complete web analytics toolkit'. Available From http://www.alexa.com Accessed 28/06/2015.

Badgett, M., Boyce, M.S. \& Kleinberger, H. (2007) 'Turning Shoppers into Advocates', IBM Institute for Business Value, Armonk, NY.

Berry, L., Carbone, L. \& Haeckel, S. (2002) 'Managing the total customer experience', MIT Sloan Management Review, 43, 3, 85-89.

Chang, H. H., \& Chen, S. W. (2008) 'The impact of customer interface quality, satisfaction and switching costs on e-loyalty: internet experience as a moderator', Computers in Human Behavior, 24, 6, 2927-2944.

Cho, N. and Park, S. (2001) Development of electronic commerce user-consumer satisfaction index (ECUSI) for internet shopping, Industrial Management and Data Systems, 101, 8, 400-406.

Constantinides, E. (2004) 'Influencing the online customer's behaviour: the Web experience', Journal of Internet Research, 14, 2, 111-126.

Demangeot, C. and Broderick, A. J. (2006), Exploring the experiential intensity of online shopping environments, Qualitative Market Research: An International Journal, 9, 4, 325-351.

Edvardsson, B. (2005) 'Service Quality: Beyond congnitve assessment'. Managing Service Quality, 15, 2, 127-131.

Edvardsson, B., \& Gustafsson, A. \& Roos, I. (2005) 'Service portraits in service research - a critical review'. International Journal of Service Industry Management, $16,1,107-121$.

Faiola, A., Newlon, C., Pfaff, M., \& Smyslova, O. (2013) 'Correlating the effects of flow and telepresence in virtual worlds: Enhancing our understanding of user behaviour in game-based learning'. Computers in Human Behaviour, 29, 1113-1121.

Fan, Q., Lee, J. Y., \& Kim, J. I. (2013) The impact of website quality on flow related online shopping behaviours in C2C marketplaces, Managing Service Quality, 23, 5, 364-387. 
Flavian-Blanco, C., Gurrea-Sarasa, R. \& Orus-Sanclemente, C. (2011). 'Analyzing the emotional outcome of the online search behaviour with search engines'. Computers in Human Behaviour, 27, 540-551.

Greenberg, P. (2010): 'The impact of CRM 2.0 on customer insight'. Journal of Business \& Industrial Marketing, 25, pp.410-419.

Gronroos, C., \& Voima, P. (2013) 'Critical Service logic: Making sense of value creation and co-creation'. Journal of the Academy of Marketing Science, 41, 133-150

Hassanein, K., and Head, M. (2007) 'Manipulating percieved social presence through the web interface and its impact on attitude towards online shopping'. International Journal Human Computer Studies, 65, 689 - 708.

Hoffman, D. L., \& Novak, T. P. (2009): 'Flow Online: Lessons Learned and Future Prospects'. Journal of Interactive Marketing, 23, pp.23-34.

Izard, E. (1977) 'Human Emotions', Plenum Press, New York, NY.

Kuhlthau, C. C. (1994) 'Students and the Information Search Process: Zones of intervention for Librarians'. Advances in Librarianship, 18, 57-72.

Kuhlthau, C. C. (2004): Seeking meaning: a process approach to library and information services, $2^{\text {nd }}$ Edition, Libraries Limited, Westport.

Kuhlthau, C. C., and Heinstrom, J., and Todd, R. J. (2008) The information search process' revisited: is the model still useful? Information Research, 13, 4, paper 355.

Klaus, P. (2013) 'The case of Amazon.com: towards a conceptual framework of online customer service experience (OCSE) using the emerging consensus technique (ECT)'. Journal of Services Marketing, 47, 6, 433-457.

Lee, A. S., \& Jeong, M. (2010): 'Effects of e-servcescape on customers flow experiences'. Journal of Hospitality and Tourism Technology, 3, pp.47-59.

Lee, G., G. \& Lin, H., F. (2005) 'Impact of organisational learning and knowledge management factors on e-business adoption', Management Decision, 43, 2, 171 188.

Lee, C. H., \& Crange, D. A. (2011) 'Personalisation - privacy paradox: The effects of personalisation and privacy assurance on customer responses to travel web sites', Tourism Management, 32, 987-994.

Liu, Y., \& Shrum, L. J. (2002): 'What Is Interactivity and Is It Always Such a Good Thing? Implications of Definition, Person, and Situation for the Influence of Interactivity on Advertising Effectiveness'. Journal of Advertising, 31, pp.53-64. 
McMillan, S. J., \& Hwang, J. S. (2002): 'Measures of perceived interactivity: an exploration of the role of direction of communication, user control, and time in shaping perceptions of interactivity'. Journal of Advertising, 31, pp.29-42.

Meyer, C., \& Schwager, A. (2007) 'Understanding Customer Experience'. Harvard Business Review, 85, 2, 116-126.

Mehrabian, A. \& Russell, J. (1974) 'Approach to Environmental Psychology', MIT Press, Cambridge, MA.

McLean, G. J. and Wilson, A. (2015) An investigation on the online customer experience - the role of social interaction, Proceedings of QUIS14 Accelerate the Impact of Service Research.

Mossberg, L. (2007) 'A marketing approach to the tourist experience", Scandinavian Journal of Hospitality and Tourism', 7, 1, 59-74.

Nass, C., \& Moon, Y. (2000): 'Machines and Mindlessness: Social Responses to Computers'. Journal of Social Issues, 56, pp.81-103.

Nambisan, P. \& Watt, J. H. (2011) 'Managing customer experiences in online product communities', Journal of Business Research, 64, 8, 889-895.

Novak, T. P., \& Hoffman, D. L., \& Yung, Y. F. (2001): 'Measuring the customer experience in online environments: A structural equation approach'. Marketing Science, 19, 1, pp.22-42.

Pallant, J. (2013) SPSS survival manual: a step by step guide to data analysis using IBM SPSS, $5^{\text {th }}$ edition, New York.

Papadopoulou, P. (2007) Applying virtual reality for trust building e-commerce environments. Virtual Reality, 11, 107- 127.

Parasuraman, A., Zeithaml, V. A., and Berry, L. L. (1988) SERVQUAL: A multipleitem scale for measuring consumer perceptions of service quality, Journal of Retailing, 64, 1, 12-40.

Payne, A., Storbacka, K. \& Frow, P. (2008), 'Managing the co-creation of value', Journal of the Academy of Marketing Science, 36, 83-96.

Rafaeli, S. (1988): Interactivity: From New Media to Communication, in Advancing Communication Science: Merging Mass and Interpersonal Processes, R.P. Hawkins, J.M. Wiemann, and S. Pingree, eds. Newbury Park, CA: Sage Publications, pp.110 34.

Reeves, B., and Nass, C. (1996) The Media Equation: How People Treat Computers, Television, and New Media Like Real People and Places. Cambridge University Press. 
Rose, S., Clark, M., Samouel, P., \& Hair, N. (2012): 'Online Customer Experience in e-Retailing: An empirical model of Antecedents and Outcomes'. Journal of Retailing, 88, pp.308-322.

Schmitt, B. (1999): 'Experiential Marketing'. Journal of Marketing Management, 15, pp.53-57

Skadberg, Y. X., and Kimmell, J. (2004) Visitors' Flow Experience while browsing a website: Its measurement, contributing factors and consequences. Computers in Human Behaviour, 20, 403-422.

Smith, D. N., and Sivakumar, K. (2004) Flow and internet shopping behavior: a conceptual model and research propositions, Journal of Business Research, 57, 1, 1199-1208.

Song, J. H., \& Zinkhan, G. (2008): 'Determinants of Perceived Web Site Interactivity'. Journal of Marketing, 72, pp.99-113.

Tabachnick, B. G., \& Fidell, L. S. (2007): 'Using multivariate statistics'. $5^{\text {th }}$ Ed. Boston: Allyn and Bacon.

Truel, O., \& Connelly, C.E. (2013): 'Too busy to help: Antecedents and outcomes of interactional justice in web-based service encounters'. International Journal of Information Management, 33, pp.674-683.

Tombs, A., \& McColl-Kennedy, J. R. (2003): 'Social-servicescape conceptual model'. Marketing Theory, 3, 4, pp.447-475.

Vargo, S. L., \& Lusch, R. F. (2006) 'Service-dominant logic: what it is, what it is not, what it might be', in Lusch, R. F. and Vargo, S. L. (Eds), The Service-Dominant Logic of Marketing: Dialog, Debate, and Directions, M.E. Sharpe, New York, NY, pp. 43-56.

Verhoef, P., Lemon, K., Parasuraman, A., Roggeveen, A., Schlesinger, L. \& Tsiros, M. (2009): 'Customer experience: determinants, dynamics and management strategies', Journal of Retailing, 85, 1, pp.31-41.

Voss, C., Roth, A. V. \& Chase, R.B. (2008) 'Experience, service operations strategy, and services as destinations: foundations and exploratory investigation', Production and Operations Management, 17, 247-66.

Wang, Y. J., Hernandez, M. D., \& Minor, M. S. (2010) 'Web Aesthetics effects on percieved online service quality and satisfaction in an e-tial environment: The moderating role of purchase task'. Journal of Business Research, 63, 935-942.

Watson, D., Clark, L. and Tellegen, A. (1988), Development and validation of brief measures of positive and negative affect: the PANAS scales, Journal of Personality and Social Psychology, 54, 1063-70. 
Weinreich, H., Obendorf, H., Herder, E., and Mayer, M. (2008) Not quite the average: an empirical study of Web use. ACM Transactions on the Web, 2, 1, 1-31. 